\title{
Um Estudo Paramétrico do Algoritmo Evolutivo baseado na representação Interação-Transformação para Regressão Simbólica
}

\author{
Guilherme S. I. Aldeia ${ }^{1}$, Fabrício O. de França ${ }^{1}$ \\ ${ }^{1}$ Centro de Matemática, Computação e Cognição (CMCC) \\ Heuristics, Analysis and Learning Laboratory (HAL) \\ Universidade Federal do ABC (UFABC) - Santo André, SP - Brasil \\ \{guilherme.aldeia, folivetti\}@ufabc.edu.br
}

Dada uma base de dados com variáveis explanatórias $\mathbf{x}$ e uma variável alvo $y$, onde exista uma função desconhecida $f(\mathbf{x})=y$, a regressão simbólica busca por uma função $\hat{f}(\mathbf{x})$ que se aproxime suficientemente bem de $f(\mathbf{x})$. Ela costuma ser feita por meios da programação genética, um método de busca e otimização que simula conceitos da teoria da evolução para construir e ajustar $\hat{f}(\mathbf{x})$ através da manipulação de populações de soluções, mas a forma em que as soluções são expressas (por meio de árvores sintáticas) apresenta um espaço de busca amplo e resultados pouco interpretáveis. Nesse contexto, foi introduzida recentemente uma nova representação para a regressão simbólica a Interação-Transformação (IT) — de forma a evitar esses problemas, limitando o espaço de busca em expressões simples, sendo capaz de retornar resultados com maior interpretabilidade que se mantém competitivos com a literatura. Algoritmos de regressão simbólica apresentam um importante compromisso entre aproximação dos dados e complexidade da função encontrada. Essa representação foi usada no contexto de um algoritmo evolutivo, com a finalidade de encontrar expressões concisas que tenham um erro de aproximação pequeno e resultados competitivos com a literatura. Em [Aldeia and de França 2020], os autores investigaram a influência dos hiper-parâmetros do algoritmo evolutivo proposto sobre os resultados, em termos de erro de aproximação e complexidade da função simbólica encontrada. Os resultados mostraram que o número máximo de termos é mais importante que o limite de expoentes permitido, e existe um limite onde aumentar o tamanho da expressão gera benefícios, podendo ser explicado pelo overfit. Como o limite dos expoentes tem menor influência, ele pode ter um valor definido como padrão sem impactar nos resultados, mas diminuindo a complexidade das funções em termos de sua interpretabilidade.

\section{Referências}

Aldeia, G. S. I. and de França, F. O. (2020). A parametric study of interactriontransformation evolutionary algorithm for symbolic regression. In 2020 IEEE World Congress on Computational Intelligence (WCCI). IEEE. O artigo foi aceito para publicação. 